\title{
Artificial Intelligence as a Challenge for Industries, Economy and Society
}

\author{
Irina V. Alyoshina \\ Department of Marketing \\ State University of Management \\ Moscow, Russia \\ ialyoshina@gmail.com
}

\begin{abstract}
Artificial Intelligence changes the global landscape of technological development and wellbeing and challenges national economies and societies with hardly predictable threats.
\end{abstract}

Key words: artificial intelligence, globalization, e-platform, neural network, algorithm, digitization.

\section{ARTIFICIAL INTELLIGENCE IN INDUSTRIES' AND MARKETS' TRANSFORMATION}

In a broad sense, artificial Intelligence (AI) can be regarded as "software technologies that make a computer or robot perform equal to or better than normal human computational ability in accuracy, capacity, and speed" [1]. AI is viewed as a software that implements the tasks of finding solutions using an algorithm with the ability of selflearning. It is used for speech recognition (translation of texts, Google translator), image and face recognition (Facebook), for consulting (business and financial advice, medical services, legal advice), automated provision of public services, recruiting, credit risk assessment, psychological targeting of Internet-advertising, including political, in social media services (Cambridge Analytica). AI is used in industrial manufacturing, in transportation, in agriculture, rapidly expanding and deepening the scope of application. According to leading technology companies, the world market of AI technologies will reach $\$ 16$ billion in five years. Annually, the industry grows by $60 \%$. Now artificial neural networks are mainly used for face recognition, automatic translation from a foreign language or online consultation [2]. Association for the Advancement of Artificial Intelligence (AAAI) gives more abstract and broad definition of AI, "the scientific understanding of the mechanisms underlying thought and intelligent behavior and their embodiment in machines" [3].

One of the first resonant evidence of the success of the AI was discovered in 1997, when the IBM computer Deep Blue for the first time beat the world chess champion Garry Kasparov. In 2017 AlphaGo, created by Google, defeated the strongest player on the planet in Go. The machine analyzes a large number of factors (scenarios, variants and results) inaccessible to the human brain, which works in a simplified scheme.

Systems of AI, Internet of things, robotization and blockchain are voiced by visionaries of IT business among the main directions of technological development of a number of industries. These technologies are interrelated and interdependent. They decentralize decision-making in society and the economy, using the principle of distributed trust in the network of participants instead of the administrative vertical approach. A large number of devices, people and organizations are connected by intensive information, material, financial and other resources' flows and processes. New technologies rely on artificial neural networks, networks of computational elements ("neurons"), or systems of algorithms for complex decision makings according to the rules "if - then", improving in the process of functioning ("learning systems").

The leading IT and Internet companies of the world are engaged in research, development and implementation of artificial intelligence technologies (Google, Amazon, Facebook, Apple, Alibaba, Microsoft, SAP, IBM). All these companies use business models of the digital cloud platform, providing a platform for interaction of suppliers and consumers of goods and services, ideas. The platform acts as an intermediary for transactions of a large number of participants in various markets, charging them a fee similar to the tax. Competitiveness of the platform depends on the number and quality of participants customers and partners involved. The Internet infrastructure is international, so the global scale of operations is provided by the extraterritoriality of the Internet-infrastructure of digital platforms.

Companies working with end-users (Amazon, Apple, Google) put the development of AI and voice assistants in the center of their business models. These technologies allow to monitor and analyze consumer behavior in real time, bringing business closer to the process of consumer decision making and so to management of buying decisions.

The large audit four (PwC, EY, KPMG and Deloitte) are actively increasing their investments in the research and use of AI technologies. These technologies shorten the processing time of customer orders, facilitate Big Data analysis and identify unusual transactions, outside interference and fraudulent schemes. Image recognition, automation of accounting and of other routine tasks optimize the work of auditors.

The large audit four -(PwC, EY, KPMG and Deloitte) are actively increasing their investments in the research and use of AI technologies. These technologies shorten the processing time of customer applications, facilitate the 
analysis of large data and identify unusual transactions, outside interference and fraudulent schemes. Image recognition, automation of accounting and of other routine tasks optimize the work of auditors.

The ability to work with neural networks in the summer of 2017 was declared by G. Gref as a non-alternative criterion for hiring lawyers in Sberbank. In 2016, 450 lawyers who drafted statement of claim for the court were reduced there, and their work was transferred to neural networks. In 2017, it was planned by Sberbank to cut 3,000 lawyers, replacing the work of consultants with AI systems.

Automation and robotization of social sectors, including education and health, are able to improve the quality and efficiency of their functioning through the individualization of services, adapting them to the needs of citizens.

AI optimizes traffic flow. The systems of AI, with which cars are equipped, track the changing of the traffic situation and the actions of the driver, adapting the settings of the car. Self driving cars are already being designed without the steering wheel and pedals, threatening to leave the driver's profession in the past.

The spending of industrial manufacturing sectors on Internet of Things technologies is more than three times higher than those in the consumer sector of the economy [4]. The industrial Internet platforms of SAP, GE, Siemens transform the industries, assembling value chains on a global scale. They allow factories to link information about supplies and stocks, technical processes, repairs, safety, to analyze and optimize the operation of the chain. The growth of competition causes the integration of the platforms of individual players ("islands") into "continents", which means the potential reduction of today's dozen of the largest industrial platforms to 2-3 leading players. It is obvious that the owner of the platform not only owns almost unlimited information about the functioning of the largest companies, industries and regions, but can influence this operation.

$\mathrm{AI}$ is also used in the news industry, the media. Robot Heliograf wrote more than 800-t articles for the Wall Street Journal, and the world's largest news agency AP automated analysis of company reporting for the preparation of financial news.

AI technologies are supposed to change the structure of the global economy in the same way as computer, telecommunications and internet have already succeed to change the world. Developing countries and regions loose the advantages of cheap labor force being replaced by automation and robotization [5]. For example, Sewbot is much more productive than human worker and takes jobs from clothing industry in Bangladesh, Vietnam, India and Pakistan. AI helps the machine to perform human tasks, using robot camera as eyes like for self-driving car. Robotized factories do not need much workers in low paid jobs and may be moved in developed countries in order to be more close to target markets and consumers in US and Western Europe.

The global scale of automated manufacturing decreases cost per unit of product produced and makes the product available for increasing number of people around the world. AI makes mass customization possible and gives competitive advantage of personalized products and services for millions and billions of customers, as examples of Facebook, Amazon and Google show. As a result, Internet companies and social media services overtake mass media industry by the number of users and audience attention, and because of it, by advertising budgets. Traditional industries are pressed to be more digitized and also to use AI technologies to survive.

Education is one of the industries involved in global technological competition. Russian traditional offline universities are in quite uneasy situation with resources necessary for automation and digitization. They could hardly compete with the leading American and Western European universities in the world market of education basically because of financial resources available and environmental infrastructure.

Unless you are unable to digitize your business processes, you are unable to use AI technologies and real advantages or individualized learning path for each student. So, we need to think about digitization, because the problem of segmentation of student audience and the problem of individualization of learning in an age of growing uncertainty are more serious than it can be imagined.

\section{ARTIFICIAL INTELLIGENCE IN ECONOMY'S AND SOCIETY'S TRANSFORMATION}

Upcoming transformation of the production of goods, services, ideas based on AI systems is quite impressive and designated as the next, the fourth industrial revolution; Industry 4.0, Digital Economy. It is about radical changing the technological structure of the economy and society and, accordingly, the next serious social transformation. The development of AI assumes an increase in the automation of the work of many specialists, beginning with routine components with gradual displacement even more complex types of labor. Replacement of people with robots and intellectual decision-making systems raises public issues of employment reduction for a number of professions and rising unemployment, technological and economic inequality, unconditional income as compensation to the population for job cuts, and also robot taxation.

Leadership in the research and application of AI is a significant factor in the restructuring of industries and economies of countries and regions, as well as the geopolitical positioning of national economies. For example, China plans to become the leading world-class center in the field of AI [6] by 2030. In the summer of 2017, the Chinese government approved a three-stage plan to develop and implement AI technologies.

There is no accidental interest in the field of AI of Russian IT companies and government agencies looking for opportunities to optimize business processes. Rapid growth of AI technologies presupposes the need for specialists from different regions and social groups to participate in the study and discussion of this sphere in order to reduce the risks of social institutions' development deformation. The solution of this task on the scale of the Russian Federation supposes involvement of broad audiences of potential researchers, developers and users in the theoretical and practical issues of AI subjects. The speed and scale of AI development depend on the scale and nature of the audience's involvement, which means the need to provide broadband Internet access throughout the country. The accessibility of the Internet for the population seems to be a key task of building an Internet infrastructure as a necessary condition for the formation of a national digital economy. Like most information technologies, the development of $\mathrm{AI}$ requires the 
development of an extended market and an environment for IT services consumption, the price and availability of which is determined by the effect of the scale of their usage. The more people in Internet, the more extended market created and that is why the scale of operations too.

AI is not only a technology, but also a methodology (system of methods) and moreover, ideology (a system of ideas, values, views of a philosophical nature). The implementation of AI systems involves answering the questions "what is good and what is bad" for a person, business and society, i.e. resolving legal, ethical problems but not only technological ones. It is quite problematic to consider $\mathrm{AI}$ in isolation from the digital economy as an environment for the functioning of AI, since the AI assumes the collection and transmission of large amounts of data from a large number of sources, as well as intensive information processing and use for a multitude of subjects for real time decision-making. This requires an extended and developed information technology infrastructure, specialists of appropriate qualifications, and the rules of their work. The digital economy assumes the transformation of all spheres of society's life. AI is a tool for resolving the problems of a wide range of interrelated and interdependent spheres and systems, technical, biological, socio-economic, sociocultural, political and legal.

In terms of the degree of radical change, AI can be attributed to breakthrough, radical innovations that significantly change the life of society. And simultaneously AI is a hype, i.e. an acutely fashionable term for some circles of the society. According to IT specialists in Russia, disruptive decisions (which radically change the business model) do not take root in the traditional business environment, and therefore customers are advised not to immediately implement hype approaches, but to test them "from the side" of the main business for checking their efficiency and effectiveness.

The development of AI systems that process large data on a large number of citizens and generate the most important resource of the modern economy (information) carries the risk of a digital dictatorship to society if the information on citizens is concentrated in the hands of elites. Today, large data on citizens are collected and used by corporations for commercial purposes, including for marketing and advertising their products to people as consumers. However, manipulation of such data in the interests of elites can also change political processes, transforming democracy (distributed processing of data) into a digital dictatorship. The concentration of information about citizens in the hands of a limited circle of people (elites with the resources to collect and process large data) means the possibility of hacking (deciphering algorithms) of not just information systems (computers, banking information systems), but also human organisms with the aim of modifying them in specified purposes. Such modification carries risks for the biological and social evolution of society and that risks are far more serious than destruction of a number of professions.

\section{ARTIFICIAL INTELLIGENCE: THE AGENDA FOR HIGHER EDUCATION}

The use of artificial intelligence systems requires competences in both IT and in the field of application. This means changing the education system both at the content and at technological level and also at the organizational level. Thus, for example, the training of specialists in the IT medicine program is already conducted in a networked form, combining a medical college, an IT university and a technical university. Leading specialists in the field of medicine and medical education say that a modern medical university should train not just a doctor, but a specialist who can work with medical robots. Automation and robotization of medicine, the introduction of IT technologies (beginning from storing images on the server instead of printing) can improve the quality of health care and its effectiveness.

For most Russian universities, the movement in the development trend of AI systems should begin at least with the development of the IT infrastructure, the growth in the availability of Internet access for training and for all other spaces of university campuses. Without such a base, it is impossible to develop research and training programs, courses and materials on digital topics, including AI. At the same time, even the most IT-equipped universities as small islands of digital infrastructure can do little in the country, where the infrastructure necessary for Industry 4.0 is practically absent outside of large cities. Obviously, it is more difficult to cover the entire territory of the Russian Federation with the Internet than the territory of any Western European country. However, without solving the problem of building a digital infrastructure, the Russian economy will not be able to become digital for a long time, and the scale of the application of AI systems will not allow the technology to really function. So, the creation of an adequate digital infrastructure as a "net of roads" for digital information flows is the first step in the development of artificial intelligence in Russia and the construction of the digital economy as a whole.

\section{REFERENCES}

[1] AI definition. Retrived from http://www.businessdictionary.com/definition/artificialintelligence.html.

[2] Колганов Г. Язык нейронов. Чего ждать от искусственного интеллекта // Коммерсант. 2017. 1 августа. [Kolganov G. The language of Neurons. What to expect from artificial intelligence. // Kommersant. 2017. August 1] URL: https://www.kommersant.ru/doc/3372769?from=doc_vrez

[3] Association for the Advancement of Artificial Intelligence. URL: https://aitopics.org/search.

[4] Alessi C. GE, Siemens Vie to Reinvent Manufacturing by Harnessing the Cloud // WSJ. URL: https://www.wsj.com/articles/ge-siemensvie-to-reinvent- manufacturing-by-harnessing-the-cloud1488722402.

[5] Emont J. The Robots Are Coming for Garment Workers. That's Good for the U.S., Bad for Poor Countries // The Wall Street Journal. 2018, Feb. 16. URL: https://www.wsj.com/articles/the-robots-arecoming-for-garment-workers-thats-good-for-the-u-s-bad-for-poorcountries-1518797631 $\bmod =\mathrm{e} 2 \mathrm{fb}$.

[6] Курмукова А. Бесстрастный анализ. Может ли Россия стать лидером в сфере искусственного интеллекта // Коммерсант/ 2017. 26 сент. [Kurmukova A. Passionless analysis. Can Russia become a leader in the field of artificial intelligence? //Kommersant, 26.09.2017. September 26]. URL: https://www.kommersant.ru/doc/3421743. 